Journal of Engineering and Applied Sciences 15 (6): 1407-1420, 2020

ISSN: 1816-949X

(C) Medwell Journals, 2020

\title{
Three-Phase Renewable Energy Inverter: Control, Real-Time Simulation and Experimental Results
}

\author{
${ }^{1,2}$ Ahmed Emad-Eldeen, ${ }^{3}$ Adel A. Elbaset, ${ }^{4}$ Mustafa Abu-Zaher and ${ }^{2}$ Ramadan Mahmoud Mostafa \\ ${ }^{1}$ Department of Renewable Energy Science and Engineering, \\ Faculty of Postgraduate Studies for Advanced Science, \\ ${ }^{2}$ Department of Electronics, Faculty of Industrial Education, Beni-Suef University, \\ Beni Suef, Egypt \\ ${ }^{3}$ Department of Electrical Engineering, Minia University, Minia, Egypt \\ ${ }^{4}$ Department of Electrical, Faculty of Industrial Education, Sohag University, Sohag, Egypt
}

\begin{abstract}
This research presents a technique of converting the Direct Current (DC) to an Alternating Current (AC) for the Photovoltaic (PV) system through a designed three-phase inverter tied to the grid. As it's known, the inverter is characterized as an independent and high-quality device in addition to, considered the backbone of the Renewable Energy Sources (RESs). Therefore, this research presents a control strategy of active and reactive power using three-phase inverters which are connected to the grid. The presented control strategy is implemented by using dSPACE MicroLabBox (1202). Moreover, the laboratory results are recorded using MATLAB/Simulink Software. During the last decades, the sun has become the best ever source for generating energy as it considers a clean, renewable and environmentally friendly source, instead of depending on fossil fuel. Hence, solar energy has become the ideal searching field to sought after by scientists. This study has presented a fulfill experimental behavior for the proposed controller including curves, simulation results and conclusions according to the obtained outcomes, also all the effort accomplished in this study to achieve the basic motivation for this study which is designing a three-phase inverter characterized as complete reliability to control the active and reactive power easily, also it can Independently inject the active and reactive power into grid without exciting for any distortion in the wave forms. The presented control strategy for the active and reactive power is executed by using indirect power control. Where the function of the Proportional-Integral (PI) controller includes the control of error signal which is the difference between the measured current and the feeder current in order to reduce the error signal up to zero.
\end{abstract}

Key words: Three phase inverter, active power, reactive power, filter, photovoltaic, Space Vector Pulse Width Modulation (SVPWM)

\section{INTRODUCTION}

At the present time, the solar energy has become the leading source for renewable energyand is considered as the inspiration source for modern technologies and applications in most of fields around the world (Kanchev et al., 2011). As expected in the few coming years, the fossil fuel will be drained, so, the necessity of finding RESs is the most important target for most of the researchers for facing the world demands of energy and also solving the pollutions problems. As well known, the solar energy has been classified as a clean, ongoing energy source which is able to be invested in several fields and applications. The most important component in the PV technology is the three-phase inverter which has an effective role as it refines the efficiency of power transferred to the grid as well as some inverters operate using the method of active power injection
(Suyata et al., 2015), after a complete study for multifunction inverters specific modes have been classified as follow:

- The mode of maximum active power

- Reactive power providing mode relies on the voltage

- Maximum reactive power

- Reactive power and power factor estimation

The technique of grid connectivity with a three-phase inverter and improving the performance of included factors (Ozbay et al., 2017). In this study, the guiding principles for the phase locked loop (pll) scheme and the space vector are illustrated. The (pll) is the responsible part for collecting the data of the variable factors for the grid like; frequency, voltage amplitude, current amplitude and phase angle, so that, it can be easy to control the whole system (Suyata and Po-Ngam, 2014). It is

Corresponding Author: Ahmed Emad-Eldeen, Department of Electronics, Faculty of Industrial Education, Beni-Suef University, Beni Suef, Egypt 
necessary to transfer the maximum power generated from the PV array to the grid. The most common controllers that have been used in grid-connected three-phase inverters are (PI, PID controller). This study briefly discusses the function of the PI controller, its function is to algorithmically compute the values of error through making the comparison between the registered values of the measured current and the source current, thus, it decreases the error percentage up to zero.

The control strategies of power for the Voltage Source Inverter (VSI) includes two basic types the direct and the indirect control (Sarkar and Dalvi, 2017). The indirect control type depends on the modulation of voltage like Space Vector Modulation (SVM) or sinusoidal (PWM) as it calculates the operating and stopping periods for the switches of inverter during the switching duration and that happens within the estimation for the voltage source such as the Voltage Oriented Control (VOC) (Susheela and Kumar, 2017). On the other hand, the type of direct power control depends basically on the sliding mode structure and the technique of the Direct Torque Control (DTC) which is implemented by the electrical devices on the driving regulation. One of the disadvantages is that the value of switching frequency is not constant. The main function of the dSPACE MicroLabBox is to perform accurate calculations for power and also it is responsible for several functions such as developing and checking the power controllers and receiving data and dealing with the operations in a simple and efficient method. The pattern of dSPACE provides perfect schematic arrangement, also it improves the software using the MATLAB emulation and the empiricist controlling equipment. This research illustrates the evaluation, measurements, structures designs, laboratory results, observations, conclusions and analysis for the suggested control method.

The experiments and procedures of measurements and recording results of this study were carried out in the main laboratory of industrial education at Sohag University in order to achieve the main motivation for this study which is represented in designing a three-phase inverter connected to the grid with a perfect ability of controlling the injection procedure for active and reactive power into grid without any distortion. After acquaintance with the previous related contribution for the subject of the three phase inverter connected to the grid, a particular steps have been designed to implement the proposed strategy for this study to reach the desired results.

In order to secure transferring the energy to the grid through the dc connection, the inverter is used to convert the power from DC to AC form in the final phase (Blaabjerg et al., 2004, 2011; Magdy et al., 2019; Carrasco et al., 2006; Ramonas and Adomavicius, 2013; Meneses et al., 2012). The three types which have the ability to control the three-phase inverters are: first one is the synchronous rotating frame $(\mathrm{d}-\mathrm{q})$, the second type is the stationary reference frame $(\alpha-\beta)$ and the third is the natural frame (a-b-c), due to the utilization of park transformation the voltages and currents of the three voltages inverter are being transformed to (d-q) reference which turns harmoniously with the grid voltage. For this reason, the inconstant factors of the three-phase inverter turn out to be DC amounts (Singh et al., 2011). The most popular used method for modulation of the three-phase inverters connected to the grid is a Space Vector Pulse Width Modulation (SVPWM). The function of this method is to control the vector of the output voltage for the inverter and also supplies the suitable paradigm for switching by selecting the ideal switching that helps to minimize the frequency of switching and this also applies to the switching losses, the SVPWM got lots of advantages. It features a fixed frequency for switching, the DC-link voltage is more accurate than the traditional sine (PWM) (Yan et al., 2011; Adzic et al., 2009). Nowadays, the PLL considers one of the most important applicated methods used for synchronization. The basic function of the PLL represented in the $(d-q)$ referral frame, the synchronization is being achieved by controlling the $(q)$ element responsible for the voltage of the grid, it is adjusted to equal zero and the error acts as (PI) input, the grid frequency represented in the output of the (PI) regulator while the grid angel is the result of the grid frequency integration which is used to generate the synchronous source current (Chung, 2000; Guo and Wu, 2013; Moukhtar et al., 2018; Pastor and Dudrik, 2013).

In this study, the modulation technique of SVPWM is presented. In case of existing of harmonics, the axis of (q, d) for the currents of the grid related and that would affects the grid performance for current and to avoid this problem to occur, the axis of (d, q) for currents which included in the decoupled elements for the current controller of the grid could be replaced with the (d, q) axis of source currents for the grid (Yao et al., 2015).

\section{MATERIALS AND METHODS}

Connection model of a three-phase inverter to the grid: The three-phase inverter connected to the grid and the electrical circuit are illustrated in Fig. 1, the $\left(d_{c}\right)$ voltage source is connected to the inverter which represented as $\left(\mathrm{V}_{\mathrm{dc}}\right)$, also the whole system structure includes power switches there are six switches $\left(S_{1}: S_{6}\right)$ and there are the inductors of line filter (lg), Fig. 1 explains the bond that gather the power source, the produced voltage for the inverter and the currents of line in the stationary source frame.

The designed structure of the electrical circuit for a three-phase inverter tied to the grid is shown in Fig. 1. Whereas the terminal voltages of the three-phase inverter are $V_{a}, V_{b}$ and $V_{c}$ while the terminal voltages of the grid are as follow: $e_{a}, e_{b}$ and $e_{c}$. The generated currents of the inverter which are being transferred to the grid are: $\mathrm{i}_{\mathrm{a}}, \mathrm{i}_{\mathrm{b}}$ and $\mathrm{i}_{\mathrm{c}}$. 


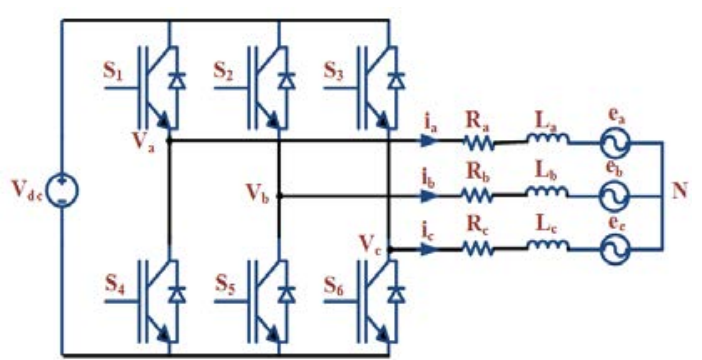

Fig. 1: Connection of three-phase inverter to the grid

Implementation of Park and inverse Park transformations in order to achieve the conversion between the two-phases for the stationary frame reference of the frame and also the synchronization for the two phases with reference frame as follow:

$$
\left[\begin{array}{l}
\mathrm{e}_{\mathrm{a}} \\
\mathrm{e}_{\mathrm{b}} \\
\mathrm{e}_{\mathrm{c}}
\end{array}\right]=\left[\begin{array}{c}
v_{\mathrm{a}} \\
v_{\mathrm{b}} \\
v_{\mathrm{c}}
\end{array}\right]-\mathrm{R}\left[\begin{array}{l}
\mathrm{i}_{\mathrm{a}} \\
\mathrm{i}_{\mathrm{b}} \\
\mathrm{i}_{\mathrm{c}}
\end{array}\right]-\mathrm{L} \frac{\mathrm{d}}{\mathrm{dt}}\left[\begin{array}{c}
\mathrm{i}_{\mathrm{a}} \\
\mathrm{i}_{\mathrm{b}} \\
\mathrm{i}_{\mathrm{c}}
\end{array}\right]
$$

From Eq. 1, the stationary reference frame can be transformed into the $\mathrm{d}-\mathrm{q}$ rotating reference frame using parks transformation. By using Clark transformation, we can obtain as in Eq. 2-5:

$$
\begin{gathered}
{\left[\begin{array}{l}
\mathrm{e}_{\alpha} \\
\mathrm{e}_{\beta}
\end{array}\right]=\frac{2}{3}\left[\begin{array}{ccc}
1 & -\frac{1}{2} & -\frac{1}{2} \\
0 & \frac{\sqrt{3}}{2} & -\frac{\sqrt{3}}{2}
\end{array}\right]\left[\begin{array}{l}
\mathrm{e}_{\mathrm{a}} \\
\mathrm{e}_{\mathrm{b}} \\
\mathrm{e}_{\mathrm{c}}
\end{array}\right]} \\
{\left[\begin{array}{l}
\mathrm{e}_{\alpha} \\
\mathrm{e}_{\beta}
\end{array}\right]=\frac{2}{3}\left[\begin{array}{lll}
1 & -\frac{1}{2} & -\frac{1}{2} \\
0 & \frac{\sqrt{3}}{2} & -\frac{\sqrt{3}}{2}
\end{array}\right]=\left[\begin{array}{l}
\mathrm{v}_{\mathrm{a}}-\mathrm{L} \frac{\mathrm{di}_{\mathrm{a}}}{\mathrm{dt}}-\mathrm{Ri}_{\mathrm{a}} \\
v_{\mathrm{b}}-\mathrm{L} \frac{\mathrm{di}_{\mathrm{b}}}{\mathrm{dt}}-\mathrm{Ri}_{\mathrm{b}} \\
v_{\mathrm{c}}-\mathrm{L} \frac{\mathrm{di}_{\mathrm{c}}}{\mathrm{dt}}-\mathrm{Ri}_{\mathrm{c}}
\end{array}\right]} \\
{\left[\begin{array}{l}
\mathrm{e}_{\alpha} \\
\mathrm{e}_{\beta}
\end{array}\right]=\left[\begin{array}{l}
\mathrm{X}_{\mathrm{d}} \\
\mathrm{X}_{\mathrm{q}}-\mathrm{L} \frac{\mathrm{di}_{\alpha}}{\mathrm{dt}}-\mathrm{Ri}_{\alpha} \\
v_{\beta}-\mathrm{L} \frac{\mathrm{di}_{\beta}}{\mathrm{dt}}-\mathrm{Ri}_{\beta}
\end{array}\right]=\mathrm{T}\left[\begin{array}{l}
\mathrm{X}_{\alpha} \\
\mathrm{X}_{\beta}
\end{array}\right],\left[\begin{array}{l}
\mathrm{X}_{\alpha} \\
\mathrm{X}_{\beta}
\end{array}\right]=\mathrm{T}^{-1}\left[\begin{array}{l}
\mathrm{X}_{\mathrm{d}} \\
\mathrm{X}_{\mathrm{q}}
\end{array}\right]}
\end{gathered}
$$

Where:

$\mathrm{X}$ : The inconstant

$\mathrm{T}$ : The conversion to matrix structure

$$
T=\left[\begin{array}{cc}
\cos \omega t & \sin \omega t \\
-\sin \omega t & \cos \omega t
\end{array}\right], T^{-1}=\left[\begin{array}{c}
\cos \omega t-\sin \omega t \\
\sin \omega t \cos \omega t
\end{array}\right]
$$

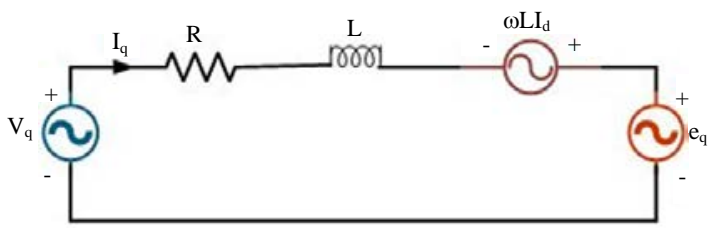

Fig. 2: Inverter d-axis voltage

$$
\begin{gathered}
{\left[\begin{array}{l}
\mathrm{e}_{\mathrm{d}} \\
\mathrm{e}_{\mathrm{q}}
\end{array}\right]=\mathrm{T}\left[\begin{array}{c}
\mathrm{v}_{\alpha}-\mathrm{L} \frac{\mathrm{di}_{\alpha}}{\mathrm{dt}}-\mathrm{Ri}_{\alpha} \\
\mathrm{v}_{\beta}-\mathrm{L} \frac{\mathrm{di}_{\beta}}{\mathrm{dt}}-\mathrm{Ri}_{\beta}
\end{array}\right]} \\
{\left[\begin{array}{l}
\mathrm{e}_{\mathrm{d}} \\
\mathrm{e}_{\mathrm{q}}
\end{array}\right]=\mathrm{T}\left[\begin{array}{l}
v_{\alpha} \\
v_{\beta}
\end{array}\right]-\mathrm{T}\left[\begin{array}{l}
\mathrm{L} \frac{\mathrm{di}_{\alpha}}{\mathrm{dt}} \\
\mathrm{di} \frac{\mathrm{d}_{\beta}}{\mathrm{dt}}
\end{array}\right]-\mathrm{T}\left[\begin{array}{l}
\mathrm{Ri}_{\alpha} \\
\mathrm{Ri}_{\beta}
\end{array}\right]} \\
{\left[\begin{array}{l}
\mathrm{e}_{\mathrm{d}} \\
\mathrm{e}_{\mathrm{q}}
\end{array}\right]=\left[\begin{array}{l}
\mathrm{v}_{\mathrm{d}} \\
\mathrm{v}_{\mathrm{q}}
\end{array}\right]-\mathrm{LT} \frac{\mathrm{d}}{\mathrm{dt}}\left\{\mathrm{T}^{-1}\left[\begin{array}{l}
\mathrm{i}_{\mathrm{d}} \\
\mathrm{i}_{\mathrm{q}}
\end{array}\right]\right\}-\mathrm{R}\left[\begin{array}{l}
\mathrm{i}_{\mathrm{d}} \\
\mathrm{i}_{\mathrm{q}}
\end{array}\right]}
\end{gathered}
$$

Implementation of the chain rule differentiation:

$$
\begin{aligned}
& \mathrm{T} \frac{\mathrm{d}}{\mathrm{dt}}\left\{\mathrm{T}^{-1}\left[\begin{array}{l}
\mathrm{i}_{\mathrm{d}} \\
\mathrm{i}_{\mathrm{q}}
\end{array}\right]\right\}=\mathrm{TT}^{-1} \frac{\mathrm{d}}{\mathrm{dt}}\left[\begin{array}{l}
\mathrm{i}_{\mathrm{d}} \\
\mathrm{i}_{\mathrm{q}}
\end{array}\right]+\mathrm{T}\left[\frac{\mathrm{d}}{\mathrm{dt}} \mathrm{T}^{-1}\right]\left[\begin{array}{l}
\mathrm{i}_{\mathrm{d}} \\
\mathrm{i}_{\mathrm{q}}
\end{array}\right] \\
& \mathrm{TT}^{-1}=\left[\begin{array}{ll}
1 & 0 \\
0 & 1
\end{array}\right],\left[\frac{\mathrm{d}}{\mathrm{dt}} \mathrm{T}^{-1}\right]=\left[\begin{array}{cc}
-\omega \sin \omega \mathrm{t} & -\omega \cos \omega \mathrm{t} \\
\omega \cos \omega \mathrm{t} & -\omega \sin \omega \mathrm{t}
\end{array}\right] \\
& \mathrm{T}\left[\frac{\mathrm{d}}{\mathrm{dt}} \mathrm{T}^{-1}\right]=\left[\begin{array}{cc}
0 & -\omega \\
\omega & 0
\end{array}\right] \\
& {\left[\begin{array}{l}
e_{d} \\
e_{q}
\end{array}\right]=\left[\begin{array}{l}
v_{d} \\
v_{q}
\end{array}\right]-L \frac{d}{d t}\left[\begin{array}{l}
i_{d} \\
i_{q}
\end{array}\right]+\omega L\left[\begin{array}{c}
i_{q} \\
-i_{d}
\end{array}\right]-R\left[\begin{array}{l}
i_{d} \\
i_{q}
\end{array}\right]}
\end{aligned}
$$

Equation 13 can be communicated in the state space form as by Chung (2000). After that the generated voltage of the inverter in $\mathrm{d}-\mathrm{q}$ reference frame can be obtained by:

$$
\begin{gathered}
{\left[\begin{array}{c}
v_{d} \\
v_{q}
\end{array}\right]=\left[\begin{array}{l}
e_{d} \\
e_{q}
\end{array}\right]+L \frac{d}{d t}\left[\begin{array}{l}
i_{d} \\
i_{q}
\end{array}\right]-\omega L\left[\begin{array}{c}
i_{q} \\
-i_{d}
\end{array}\right]+R\left[\begin{array}{c}
i_{d} \\
i_{q}
\end{array}\right]} \\
v_{d}=e_{d}+L \frac{d i_{d}}{d t}-\omega L i_{q}+R i_{d}
\end{gathered}
$$

$$
v_{\mathrm{q}}=\mathrm{e}_{\mathrm{q}}+\mathrm{L} \frac{\mathrm{di}_{\mathrm{q}}}{\mathrm{dt}}+\omega \mathrm{Li}_{\mathrm{d}}+\mathrm{Ri}_{\mathrm{q}}
$$

Neutralization Eq. 15 and 16 represents the generated voltage of the inverter using $d-q$ synchronous reference frame as seen in Fig. 2 and 3. 


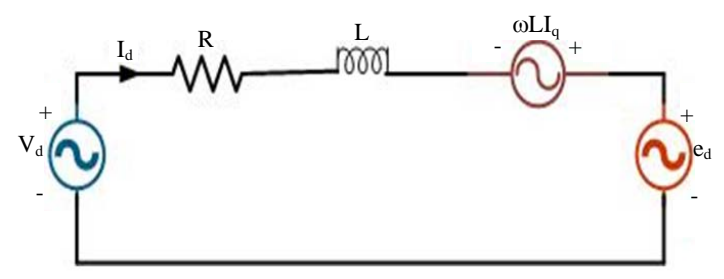

Fig. 3: Inverter q-axis voltage

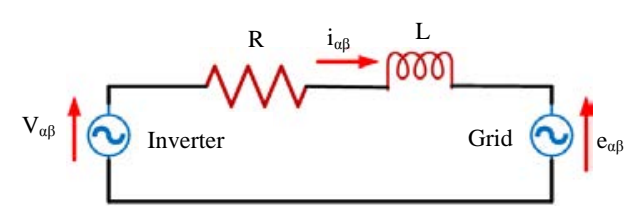

Fig. 4: Inverter prototype in the $\alpha \beta$ stationary frame

The previous equations and electrical circuits illustrate the prototype of the three-phase grid connected inverter and explain the synchronization of $d$-q reference frame. The control strategy of the active and reactive power for the inverter depending on dealing efficiently the $\mathrm{V}_{\mathrm{d}}$ and $\mathrm{V}_{\mathrm{q}}$. Figure 4 explains the circuit of the inverter prototype in the $\alpha \beta$ stationary frame.

Current control: The most widely used type of current controller is (PWM) voltage source inverter and that is owing to its advantages like: fast response, precis control, accurate execution and also the ability of producing an (AC) output in sinusoidal form by securing continuous supplies of (AC) power (Prodanovic and Green, 2003). The basic function of the current-controlled (PWM) voltage source inverters represented in imposing a mandatory path for the vector of current for the used the three-phase load. The selected strategy for the current controller greatly affects in the whole quality for the converter scheme (Salem and Atia, 2014).

During the usage of the current control, the procedure of measuring and comparison of the output currents for the inverter with the reference values of signals considered a basic step in order to generate the voltage of the inverter. The current controller considers the errors as an input, one of the PI controller functions is to control the constant amounts of dc which can be gained using (d-q) transformation. The algorithm features of the PI controller could be easily recompense the current errors for the dc amounts, the PI computes the error value by making comparison between the value of the source current and the value of the estimated current and after that the PI controller keeps on decreasing the error ratio till it reach zero. The algorithmic calculations include two fixed gains; (kp) which represents the proportional gain and (ki) which represents the integral gain:

$$
v_{d}-e_{d}+\omega L i_{q}=L \frac{d i_{d}}{d t}+R i_{d}=u d
$$

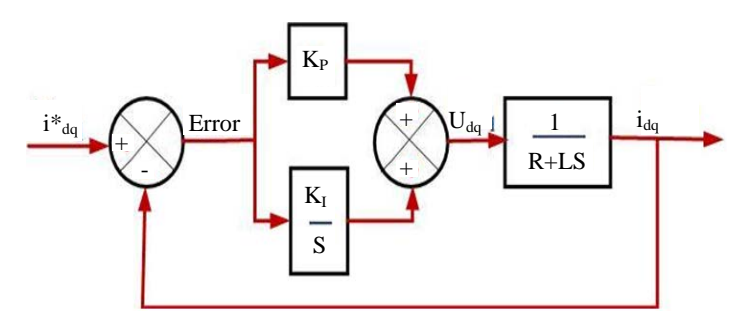

Fig. 5: Current controller schematic diagram

Therefore, the equation of the d-axis current loop can be obtained in the s-domain as follows:

$$
\frac{I_{d^{(s)}}}{U_{d^{(s)}}}=\frac{1}{R+L S}
$$

Referring to Eq. 16:

$$
\mathrm{v}_{\mathrm{q}}-\mathrm{e}_{\mathrm{q}}-\omega \mathrm{Li}_{\mathrm{q}}=\mathrm{L} \frac{\mathrm{di}_{\mathrm{q}}}{\mathrm{dt}}+\mathrm{Ri}_{\mathrm{q}}=\mathrm{uq}
$$

Thus, the equation of the s-domain transformation for the q-axis current loop could be obtained as follows:

$$
\frac{\mathrm{I}_{\mathrm{q}^{(s)}}}{\mathrm{U}_{\mathrm{q}^{(s)}}}=\frac{1}{\mathrm{R}+\mathrm{LS}}
$$

Obviously, it could be concluded that the system is classified to be a first order type and that's clearly explained in functions Eq. 18 and 20.

Figure 5 explains the scheme of the current control loop which could detect the value of the reference current in order to control the active and reactive power (Lal and Singh, 2015). The error signal acts as the input of the PI controller which can be calculated by making comparison between the source current and the factual current of the inverter in the(d-q) source frame and the transfer equation will be $(1 /(\mathrm{R}+\mathrm{LS}))$ as determined from functions as given in Eq. 18 and 20.

The algorithm controller: From Fig. 6, the voltages of grid ae recorded also the PLL is the responsible for detecting the angle of the grid which has the ability of achieving the transformation of the currents and voltages of the grid from the reference frame of the $a-b-c$ to the reference frame of the $d-q$ and that is could be achieved by using park transformation as shown in Eq. 21:

$$
\left[\begin{array}{c}
v_{\mathrm{d}} \\
v_{\mathrm{q}}
\end{array}\right]=\frac{2}{3}\left[\begin{array}{ccc}
\cos \theta & \cos \left(\theta-\frac{2 \pi}{3}\right) & \cos \left(\theta-\frac{4 \pi}{3}\right) \\
-\sin \theta & -\sin \left(\theta-\frac{2 \pi}{3}\right) & -\sin \left(\theta-\frac{4 \pi}{3}\right)
\end{array}\right]\left[\begin{array}{c}
v_{\mathrm{ga}} \\
v_{\mathrm{gb}} \\
v_{\mathrm{gc}}
\end{array}\right]
$$




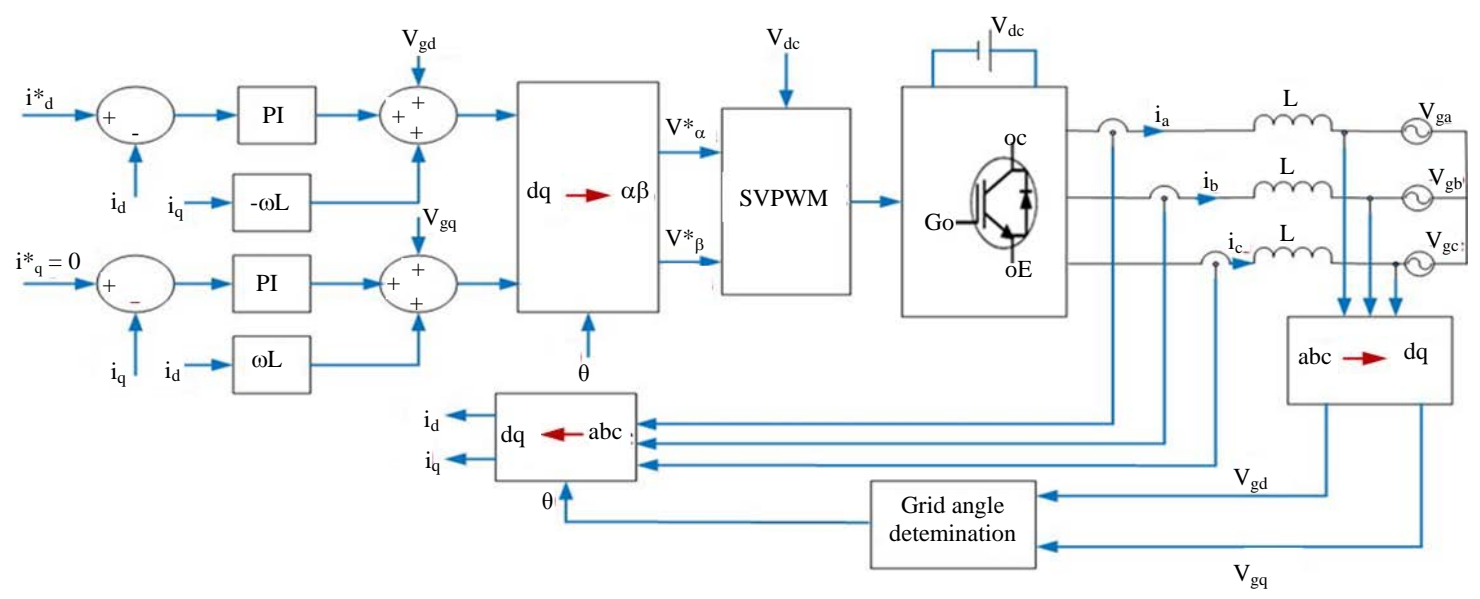

Fig. 6: Controlling schematic diagram for the inverter

In order to compute the value of error, the reference current and the $\mathrm{d}-\mathrm{q}$ currents must be measured and the PI controller receives the errors of the $\mathrm{d}-\mathrm{q}$ frame as inputs, the reference d-element of the current can determine the maximal value for the current for the grid. While the q-element of current has dominance over the flowing of the reactive power. It is adjusted to equal zero just in the case of the injection of active power, the voltage of feed forward are combined with the outputs of the PI and gathering the elements to generate the outputs voltages of the source inverter while the PI output is converted to $\alpha-\beta$ frame as shown in Eq. 22:

$$
\left[\begin{array}{l}
v_{\alpha} \\
v_{\beta}
\end{array}\right]=\left[\begin{array}{cc}
\cos \theta & -\sin \theta \\
\sin \theta & \cos \theta
\end{array}\right]\left[\begin{array}{c}
v_{d} \\
v_{q}
\end{array}\right]
$$

The voltages of the $\alpha-\beta$ frame and the d-c link are applied in the SVPWM, the $\left(\mathrm{V}_{\text {ref }}\right)$ which refers to the vector of the output voltage for the reference as seen in Fig. 7. The voltage of the source is the result of adding the $\alpha$ and $\beta$ elements and the resulted values are applied to adjust the sector for the vector of the source voltage subsequently, it could be easy to determine the degree of the vector angle.

From Fig. 7, the sectors alter every $60^{\circ}$, therefor, the only way to locate the sector of the reference vector is to estimate the angle degree of the vector. The inverter generates the voltage depending on two approaching vectors and also zero vectors, the $\left(\mathrm{V}_{1}-\mathrm{V}_{6}\right)$ are representing the active vectors while the $\left(\mathrm{V}_{0}, \mathrm{~V}_{7}\right)$ are the zero vectors, the interval for each vector can be computed for every sector.

The simulation pattern of the system: The current controller is established by the utilization of MATLAB $\backslash$ Simulink in order to execute the selected system for the connected grid as seen in Fig. 8.

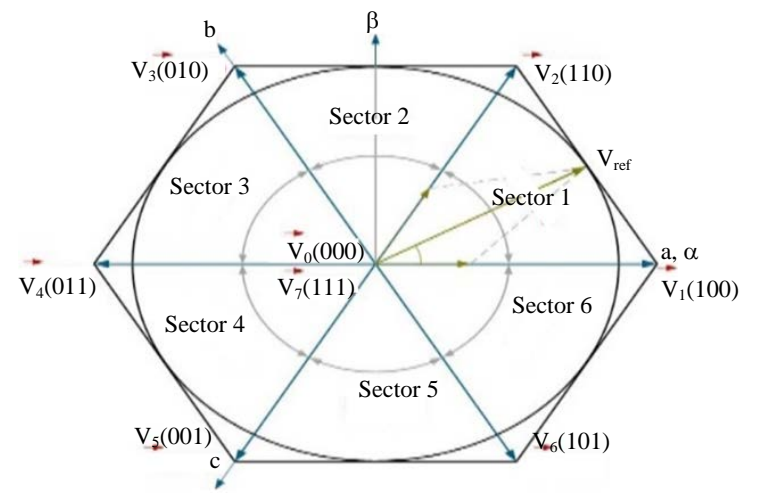

Fig. 7: Swapped sectors for SVPWM

Figure 9 shows the simulation results for the grid voltage and the wave form of the angel vector. The improved (pll) has the ability of generating an angle in conjunction with the voltage of grid, it demands nearly half a cycle for the (pll) to get the value of the steady state for the right angle.

As expected for the controlled inverter it can be classified to first order type and that's clearly explained in functions as given in Eq. 18 and 20. Therefore, the PI controller is capable for controlling the current of the inverter independently, the current controller (PI) include two fixed gains; (kp) which represents the proportional gain and (ki) which represents the integral gain. The PI controller parameters can be selected by the trial and error method as $(\mathrm{ki}=300$ and $\mathrm{kp}=50)$. The response of the current controller for step change in the source current is illustrated as shown in Fig. 10 and 11. The range of step change in the d-axis for the source current located between $3 \mathrm{~A}$ and $6 \mathrm{~A}$, while the q-axis reference current is adjusted to equal zero as seen in Fig. 10. The step change in the q-axis for reference current occurs in the range of $(-5 \mathrm{~A}$ to $-2 \mathrm{~A})$ and the $\mathrm{d}$-axis reference current is adjusted to equal zero as illustrated in Fig. 11. The current 


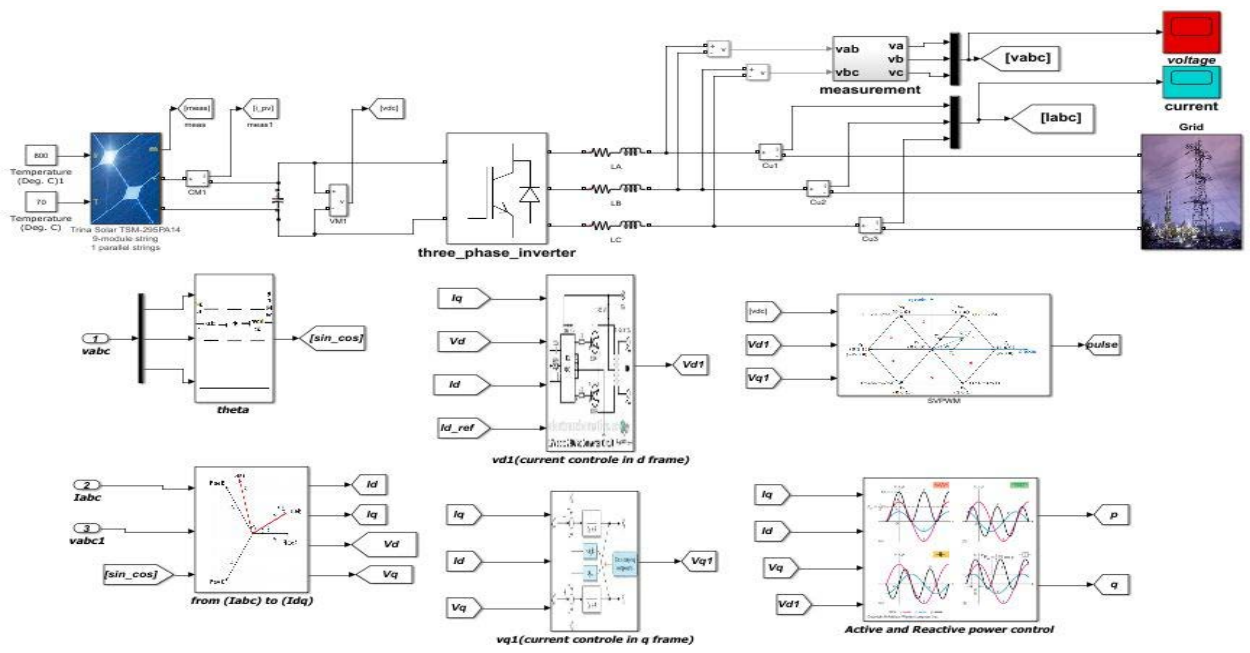

Fig. 8: The selected pattern for the simulation system of the connected grid

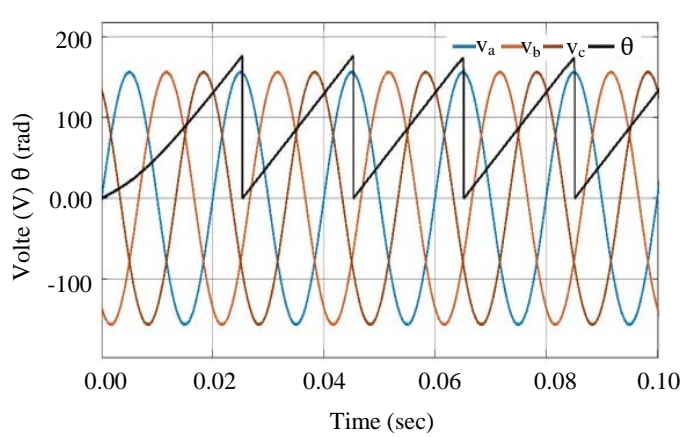

Fig. 9: Simulation results of grid voltage and (pll) grid angle

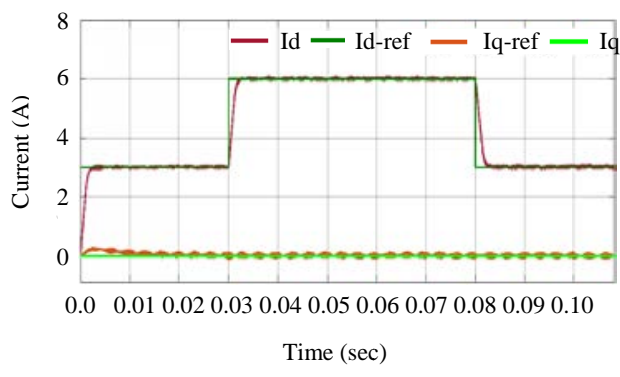

Fig. 10: Simulation results of tracking in the (d-q) frame for the step change of the (Id) reference and the (Id) measured

controller characterized as quick and has a settled dynamic response for the step change for the current. From Fig. 12, the currents of the system have been simulated and the emulation results of step change reaction for the three phase current are sketched according to the abc frame in the d-axis reference current, it can be easy to realize that the controller features a quick, steady dynamic reaction for the step changes of the current.

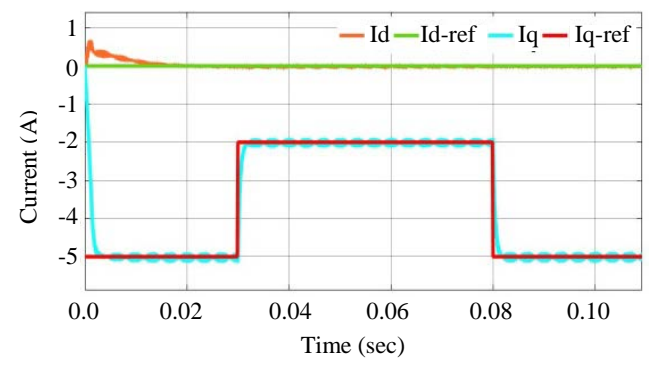

Fig. 11: Simulation results of tracking in the (d-q) frame for the step change of the (Id) reference and the (Iq) measured

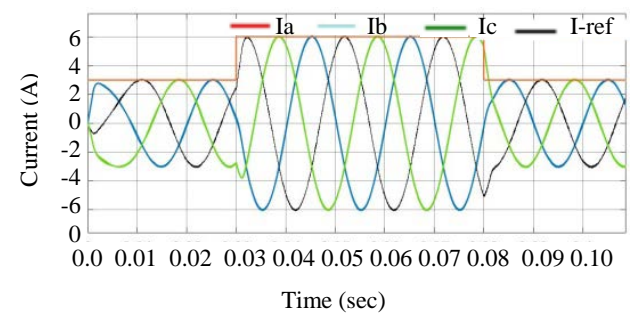

Fig. 12: Simulation outcome of the step change reaction for the three-phase current

Hardware implementation: This study presents the enforcement of whole structure loops used for execute the experimental procedures for the photovoltaic system as explained in Fig. 13, also the required components and elements to establish the system of PV panels connected to the grid to perform the experimental operation, when the modern technology is mentioned it is necessary to discuss the great role of the inverter as significant part in the PV systems, the interaction with a device like inverter requires variable knowledge of the electrical circuits and computer technology, electronic devices testing and 


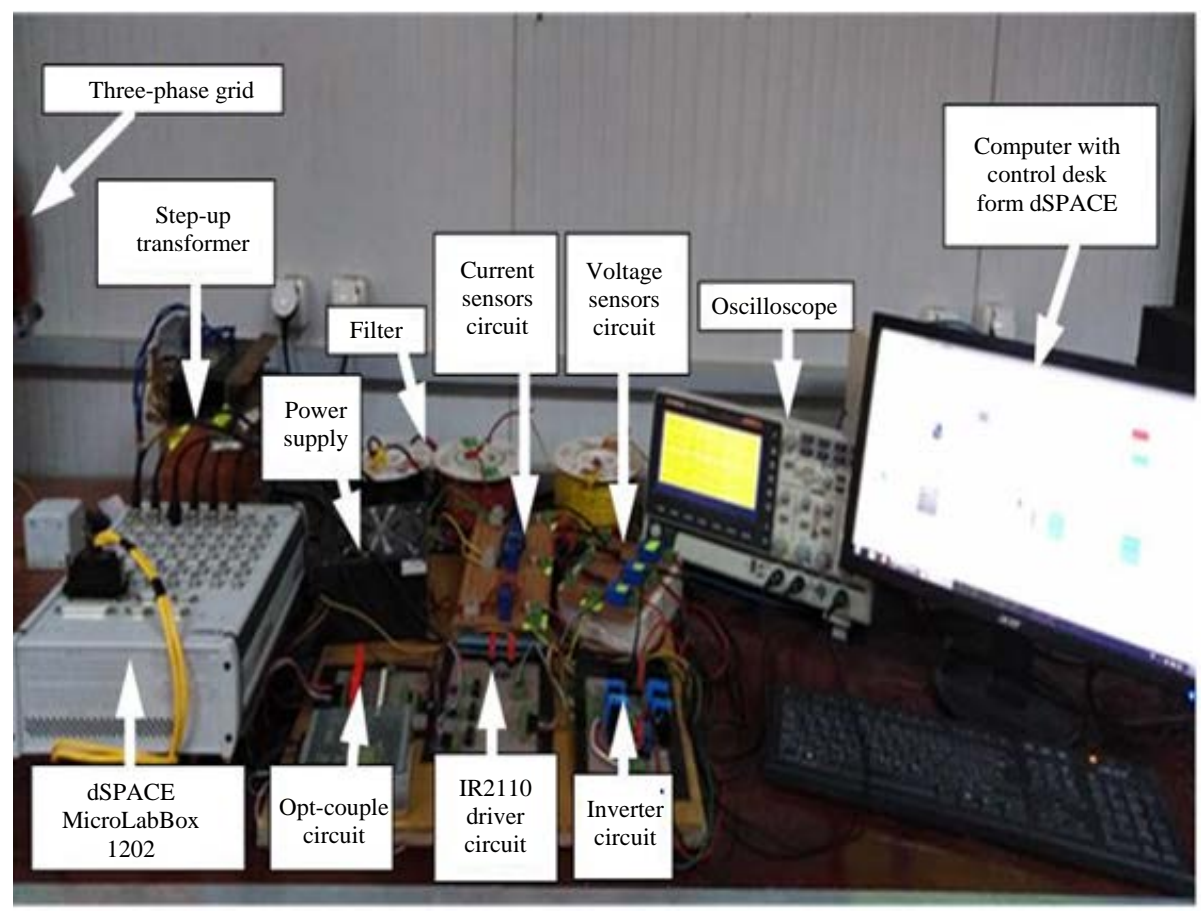

Fig. 13: Comprehensive overview of physical components

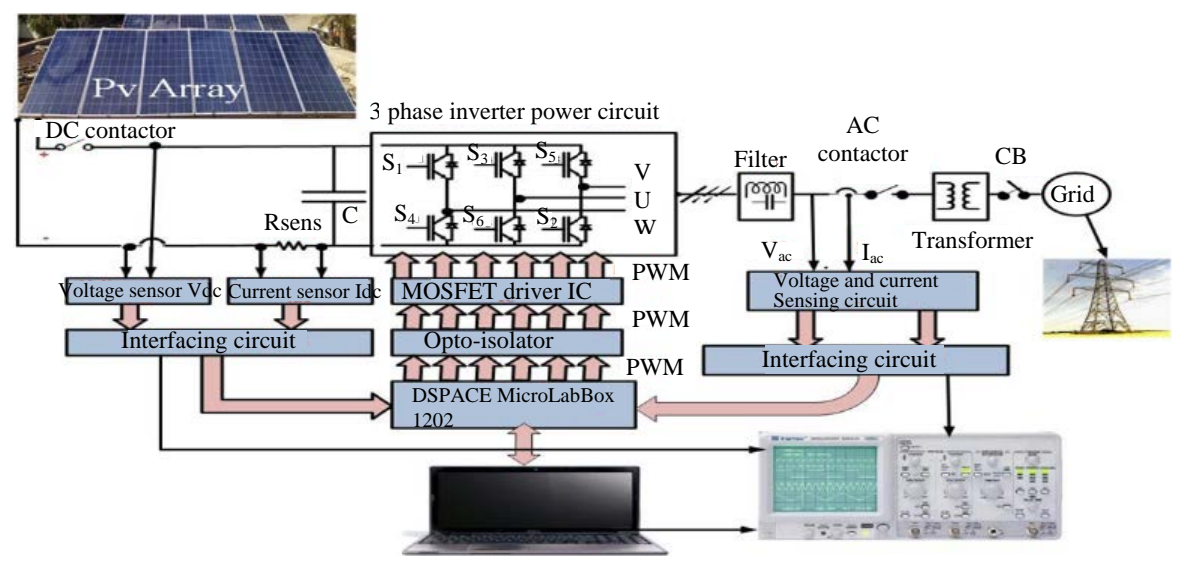

Fig. 14: Block diagram of executed single stage grid connected PV

designing the suitable programming to simulate the experimental results. This study includes two basics sections the first section concerning about the laboratory empiricist circuits which serve the whole system while the second section consists of the laboratory results and conclusions.

Figure 14 shows the PV system tied to the grid using three-phase inverter, this scheme consists of PV panels, three phase-inverter, power filter, dSPACE device, computer and oscilloscope device.

The execution of the hardware: The main circuits that compose the whole PV systems varies between the PV panels, the sensors circuits, interactions loop, control circuits, all of these circuits are connected to the outlets of the dSPACE or the inverter. Each circuit has its specific function where the variation of the excited signals such as voltage and current consequently become necessary to have feedback for these signals, the level shifter which acts as interacting circuits between the signals of PWM and inverter.

Photovoltaic system: The arrangement of the PV panels which consists of 12 modules and connected in series order, the characteristics of the PV panel are shown in Table 1. 


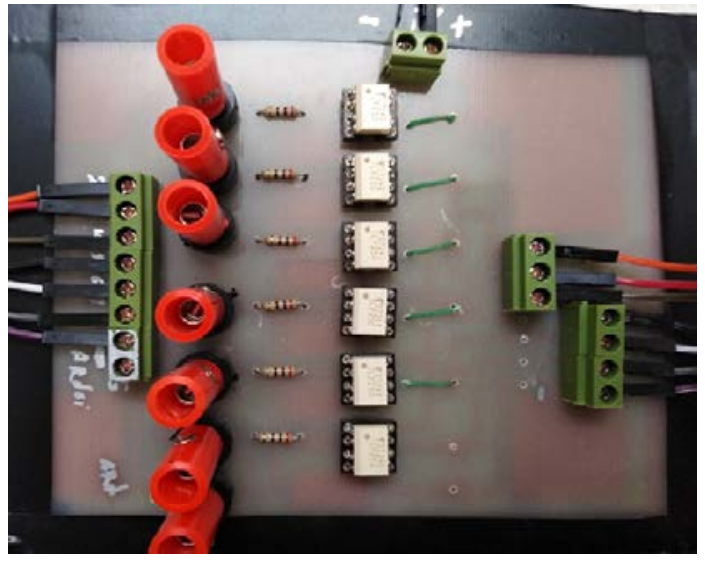

Fig. 15: Basic opt-coupler circuit

Table 1: Electrical charteristics of a PV module

\begin{tabular}{ll}
\hline Parameter & Value \\
\hline Number of series cells & 12 \\
Maximum power rating & $250 \mathrm{~W}$ \\
Open circuit Voltage (Voc) & $37.4 \mathrm{~V}$ \\
Short circuit current (Isc) & $8.63 \mathrm{~A}$ \\
Maximum power Voltage (Vmp) & $30.7 \mathrm{~V}$ \\
Maximum power current (Imp) & $8.15 \mathrm{~A}$ \\
\hline
\end{tabular}

Suggested designing for the inverter: The inverter is a very important electronically equipment, the function of the inverter is to convert the DC signals to AC signals. The generated voltage of the inverter has two forms, the first form is the (AC) voltage (e.g., sine wave and square wave) and the second form is the sine modulation (modulation sine wave). Semiconductor industry is commonly used in the power devices like the inverter, MOSFET, IGBT, transistor or thyristor. The two kinds of the generated signals for the PV connected three-phase inverters are: the low power and the medium power can be applied by the usage of square wave output signal. The high-power implementation is done by using the sine waves output signal.

Opto coupler: The used opto-coupler in this circuit characterized by rapid, continuously switching and it is flexible to be easily triggered even with the small voltages. The gate drivers function is to obtain the signal pulses from the controlling board and then amplify those signals in order to reach the required level of the switching, the power circuits and the circuits of controllers can be secluded by usage of the IGBTs and opt isolators loops. The generated (PWM) signal which come from the dSPACE of the inverters controlling switches must be isolated away from the basic DC power by usage of the device of TLP250 photo transistor coupler for isolation as explained in Fig. 15.

As seen from figure, the circuit consists of six opt-couplers which are connected. The resistance function is to restrict the current in signal.

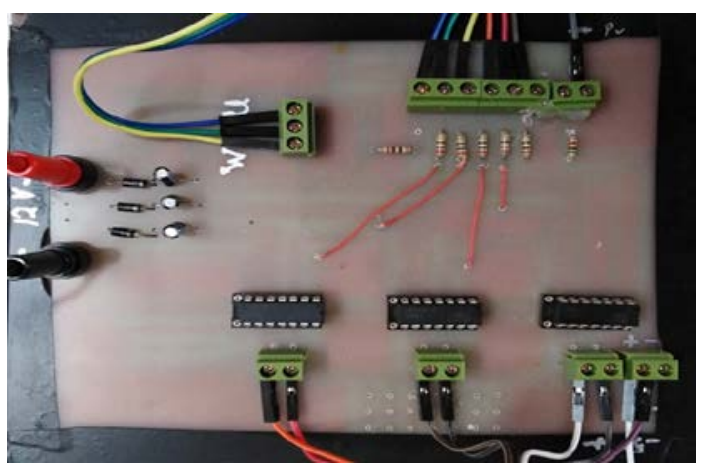

Fig. 16: IR2110 driver circuit

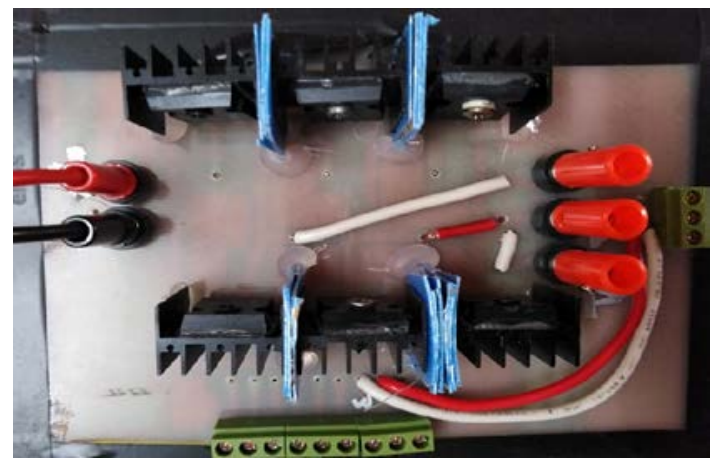

Fig. 17: Inverter circuit

MOSFET driver circuit: The suggested gate driver in this circuit is the IR2110 of the international rectifier. With 14 pins pack the IR2110 has high voltage and speed power, the MOSFET and IGBT drivers with high and low side referenced output channels. The circuit of the IGBT or MOSFET driver which is explained in the circuit of the hardware components is shown in Fig. 16.

Function of inverting circuit: The main function of the inverting circuits to convert the income dc voltage to an ac voltage. It also comes with pull-up, pull-down and activated optocoupler circuit which can be operated by using dSPACE unit. The voltage source inverter VSI takes a DC bus voltage and uses six switches arranged in three-phase legs. From the middle of each phase leg comes from the line, the voltage on these lines must be a balanced three-phase sinusoidal waveform. This is achieved by a controlled switching to the gate of the IGBTs as shown in Fig. 17. In VSIs, the input voltage is maintained constant and the amplitude of the output voltage is independent of the nature of the load. But the output current waveform as well as magnitude depends upon nature of load impedance. Three-phase Voltage Source Inverters (VSIs) are more common for providing adjustable frequency power to industrial applications as compared to single phase inverters. 


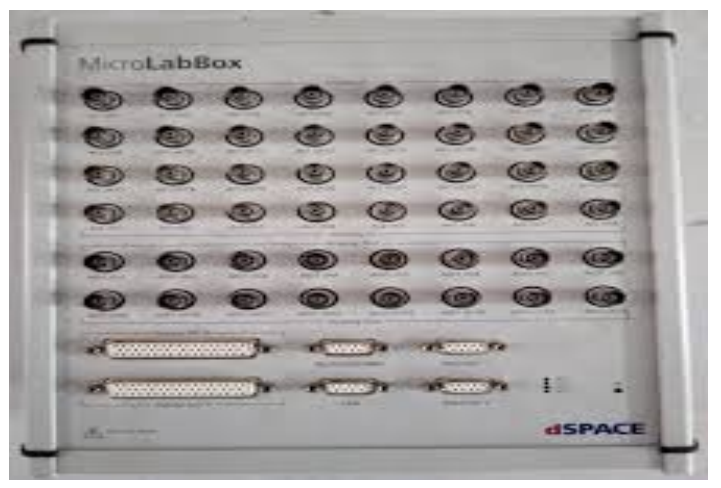

Fig. 18: dSPACE MicroLabBox (1202) controller

Table 2: The used element of the designed circuit

\begin{tabular}{ll}
\hline Component & Description \\
\hline IGBT & IRG4PC50UD \\
IGBT DRIVER & IR2110 \\
Photo coupler & TLP250 \\
\hline & \\
Table 3: The IGBT features & \\
\hline Characteristics & Values \\
\hline Device & IGBT \\
Type & IRG4PH50UD \\
Current rating (ic) & $24 \mathrm{~A}$ \\
Voltage rating (VCES) & $1200 \mathrm{~V}$ \\
VCE (on) typ. & $2.78 \mathrm{~V}$ \\
VGE & $15 \mathrm{~V}$ \\
\hline
\end{tabular}

In this research, the selected type of inverter is the three-phase inverter; this type is proposed to achieve the operation of controlling the designed circuit, the used elements are detailed in Table 2 and also the IGBT features are mentioned in Table 3.

dSPACE MicroLabBox: The proposed circuit of PWM circuit has been executed by using the dSPACE MicroLabBox (1202) as shown in Fig. 18. The dSPACE is one of the most important components in the modern technology. Where it characterized as it can perform variable calculations. Furthermore, it can examine, detect, collect data and process multi functions which serves the whole system. Platform for laboratory use, MicroLabBox that offers high computing power and comprehensive functionalities. MicroLabBox makes creating, optimizing and testing controllers and implementing data acquisition applications easy and cost-efficient for both industry and academia.

Voltage sensor: In order to estimate the generated voltages of the grid three voltage sensors are needed and the fourth sensor is used for estimating the voltage of the dc junction. The used sensors characterized are hall-effect sensors which has been made by LEM. Figure 19 illustrates the design scheme for the sensors of the voltage and its connection method.

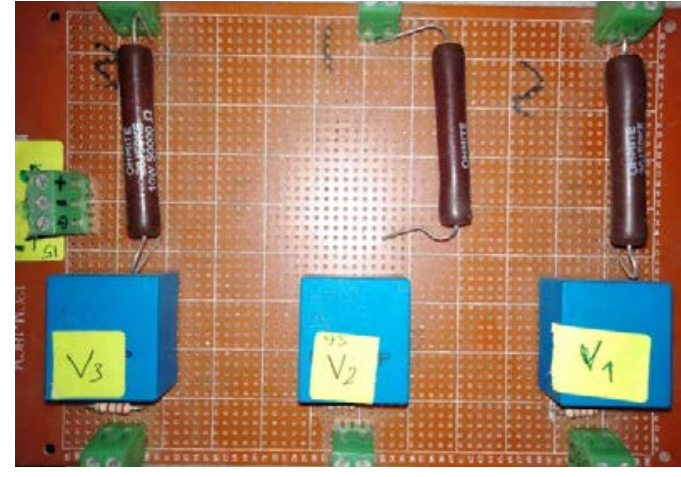

Fig. 19: Photo of the implemented voltage sensor board

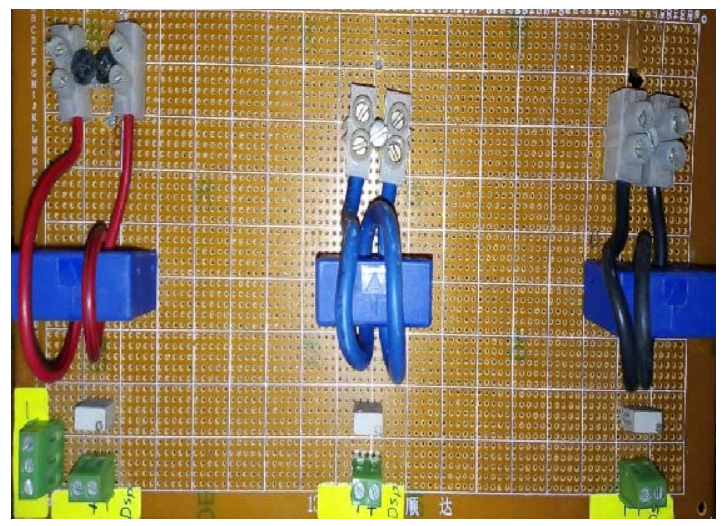

Fig. 20: Photo of the implemented current sensor board

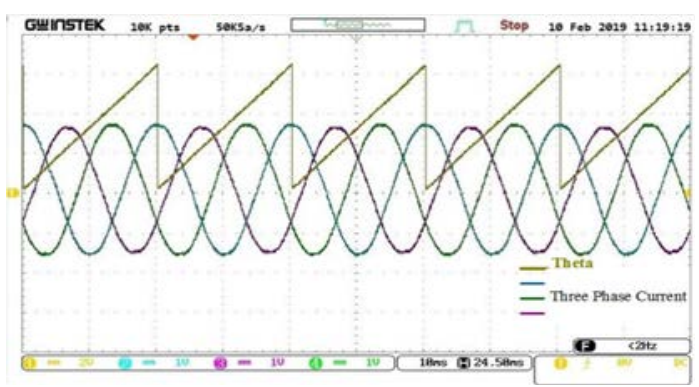

Fig. 21: Three-phase calculated voltages and angle $(\theta)$ of the grid (gauge $\mathrm{v}=100 \mathrm{v} / \mathrm{div}, \theta=2 \mathrm{rad} / \mathrm{div}$, $\mathrm{t}=10 \mathrm{msec} / \mathrm{div})$

Current sensor: Three current sensors used to measure the current injected to grid and one to measure DC current of PV. Each current sensor can measure up to 25A. The sensors are hall-effect sensors and are manufactured by LEM. The circuit of the implemented current sensor card is shown in Fig. 20.

\section{RESULTS AND DISCUSSION}

As explained in Fig. 21, the simulation results of detecting the grid theta angle $(\theta)$ and the three-phase 


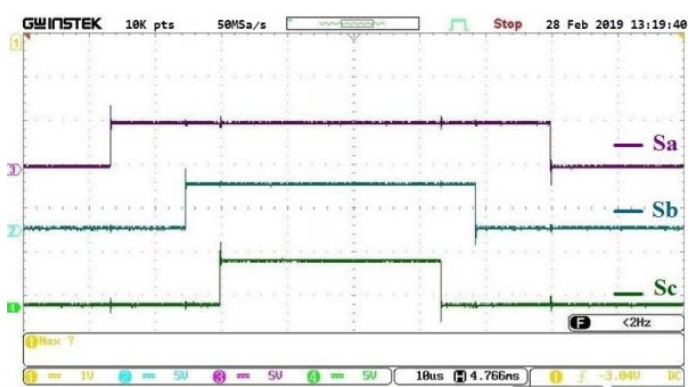

Fig. 22: Laboratory results for the (PWM) switching models for the space vector during the first sector

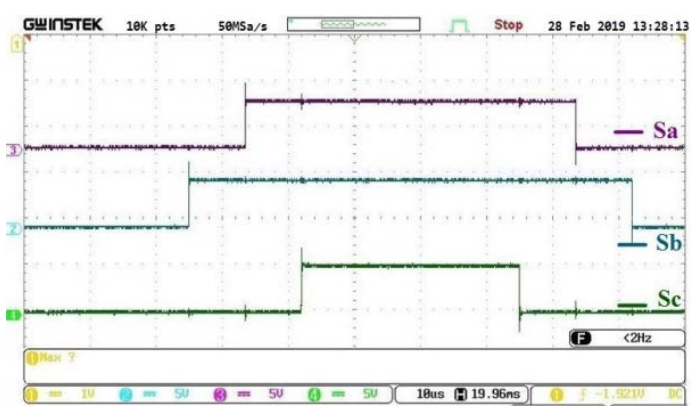

Fig. 23: Laboratory results for the (PWM) switching models for the space vector during the second sector

voltages, it is illustrated that the angle theta can be determined between $0^{\circ}$ and $360^{\circ}$. The simulation results from Fig. 22-27 shows the laboratory results of the pulsated signals starting from the first sector and ending with the sixth sector.

The active response of the current controller is explained in Fig. 28. Values of $\mathrm{ki}=300$ and $\mathrm{kp}=50$. The range of step change in the d-axis for the source current located between $3 \mathrm{~A}$ and $6 \mathrm{~A}$ while the q-axis reference current is adjusted to equal zero, the PI controller features a quick and steady response and the generated current is free of excrescent or under shooting, the active response of PI when the step change in the q-axis for reference current occurs in the range of (-5A to -2A) and the d-axis reference current is adjusted to equal zero, the results shown in Fig. 29 can confirm that the proposed system is capable of controlling both of reactive and active power. Figure 30 shows the current of the d-axis reference and the generated current of the three phase for source current step changing, the figure also show up the strength of the implemented controller to pursuit the quick alterations which occurs in the source current whilst the source current of the q-axis is adjusted to equal zero.

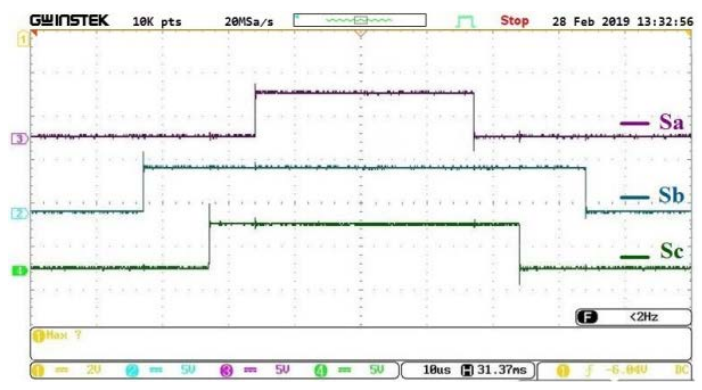

Fig. 24: Laboratory results for the (PWM) switching models for the space vector during the third sector

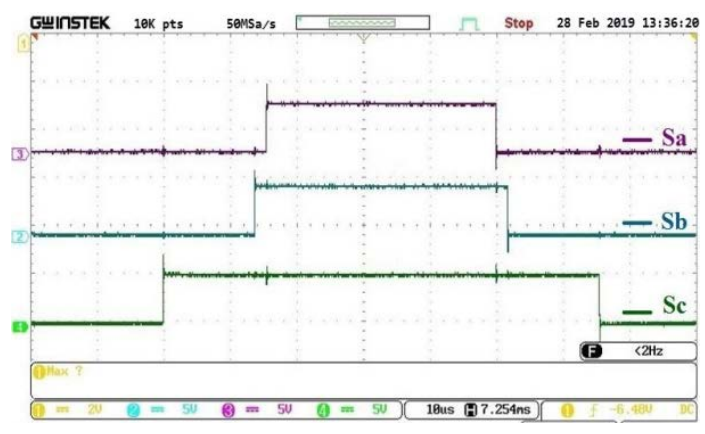

Fig. 25: Laboratory results for the (PWM) switching models for the space vector during the fourth sector

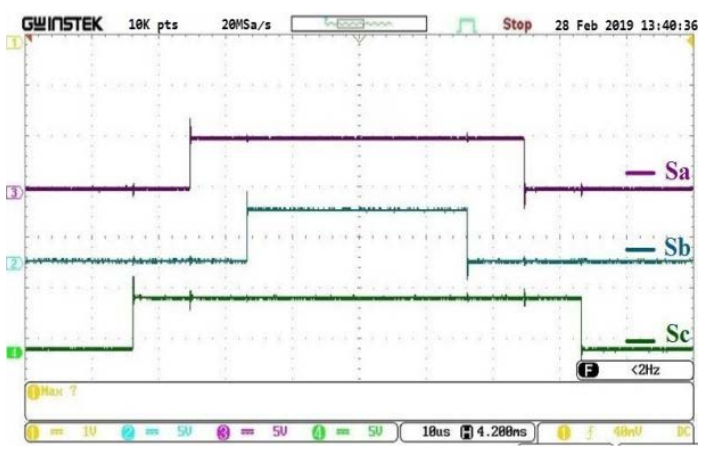

Fig. 26: Laboratory results for the (PWM) switching models for the space vector during the fifth sector

Processing of active and reactive power: There are two stages of the experiments conclusions, the first section is the results of steady state which ensure the suitable operation for the suggested controller, the second stage is the transient operation which expose the flexibility of the system for observing and follow the changes that occurs in the reference orders. 


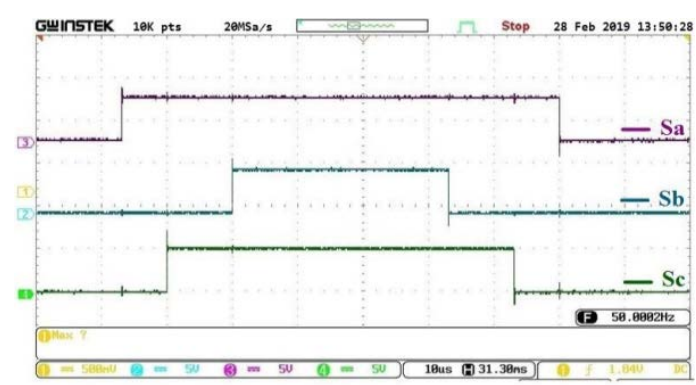

Fig. 27: Laboratory results for the (PWM) switching models for the space vector during the sixth sector

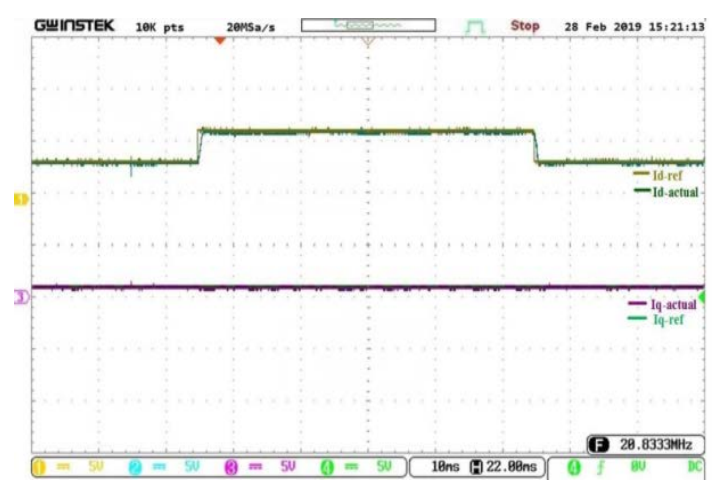

Fig. 28: Dynamic reaction for the current controller in the frame of dq for step change (Id) reference (gauge: $\mathrm{I}=5 \mathrm{~A} / \mathrm{div}, \mathrm{t}=10 \mathrm{msec} / \mathrm{div}$ )

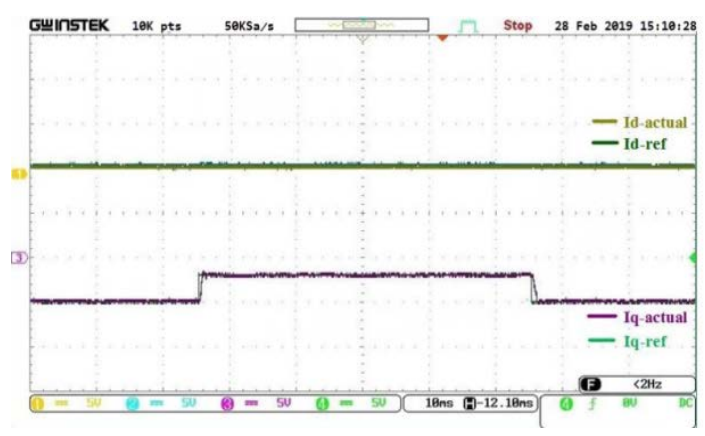

Fig. 29: Dynamic reaction for the current controller in the frame of $\mathrm{dq}$ for step change (Iq) reference (gauge: $\mathrm{I}=5 \mathrm{~A} / \mathrm{div}, \mathrm{t}=10 \mathrm{msec} / \mathrm{div}$ )

Operation of steady state: The graphs shown in Fig. 31-33 explain the laboratory results for the procedure of the steady state. These graphs explain the received active and reactive power into grid, the graphs recorded different conditions for the current and the voltage for the phase (A). In graph shown in Fig. 31 illustrate the statue of the power factor unity. While Fig. 32 shows the zero state of the power factor, the angel measurement between the voltage and the current of phase (A) is $90^{\circ}$, the

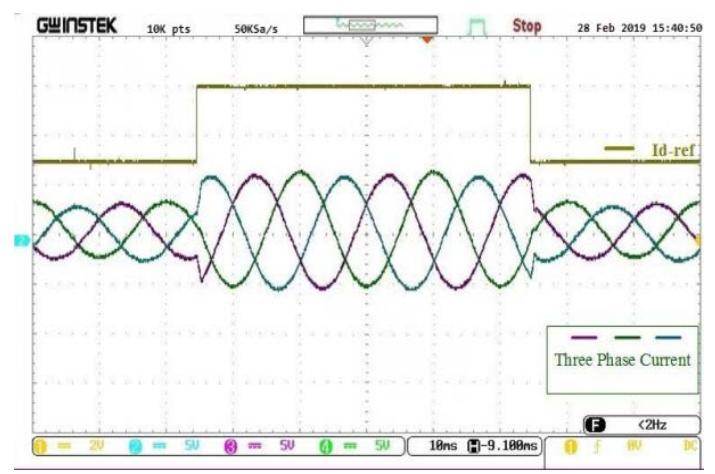

Fig. 30: Step change of generated three phase current and (Id) reference (gauge: $\mathrm{I}=5 \mathrm{~A} / \mathrm{div}, \mathrm{t}=10$ msec/div)

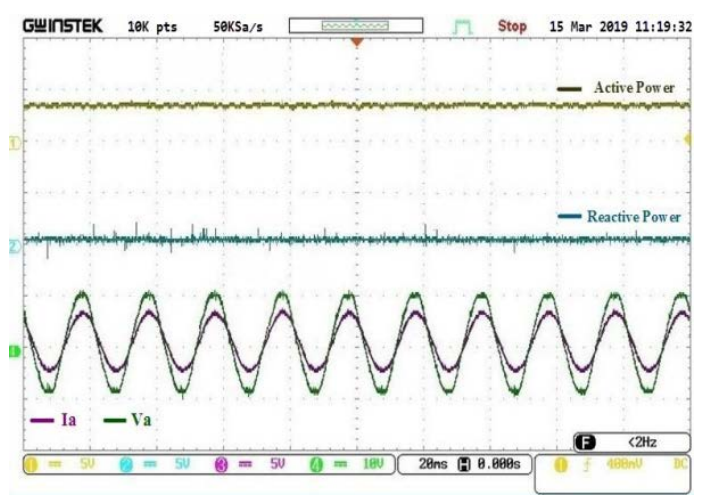

Fig. 31: Experimental stage for the steady state of the power factor unit process [Scale: $\mathrm{V}=150$ $\mathrm{V} /$ div, $\mathrm{I}=5 \mathrm{~A} / \operatorname{div}, \mathrm{P}=1000 \mathrm{~W} / \operatorname{div}, \mathrm{t}=20$ $\mathrm{msec} / \mathrm{div}]$

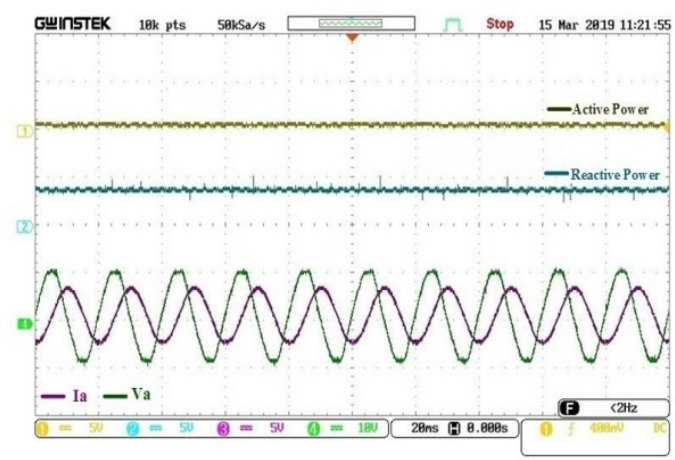

Fig. 32: Experimental stage for the steady state when the power factor equals zero [Scale: $\mathrm{V}=150$ $\mathrm{V} / \mathrm{div}, \mathrm{I}=5 \mathrm{~A} / \mathrm{div}, \mathrm{P}=1000 \mathrm{~W} / \mathrm{div}, \mathrm{t}=20$ $\mathrm{msec} / \mathrm{div}]$

operation of the power factor delay of 0.7 is shown in Fig. 33 whereas the active and reactive power are evenness whilst the current of phase (A) has a $45^{\circ}$ lagging about the voltage of phase (A). 


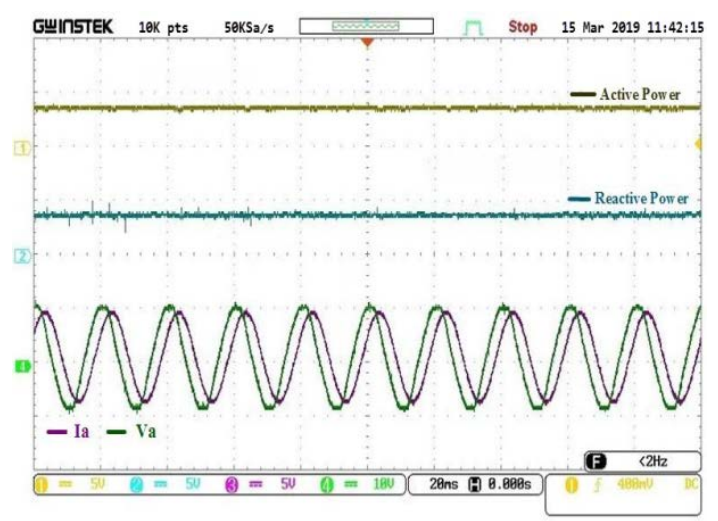

Fig. 33: Experimental stage for the steady state at the procedure of power factor 0.7 lagging [Scale: $\mathrm{V}=150 \mathrm{~V} / \operatorname{div}, \mathrm{I}=5 \mathrm{~A} / \operatorname{div}, \mathrm{P}=1000 \mathrm{~W} / \operatorname{div}$, $\mathrm{t}=20 \mathrm{msec} / \mathrm{div}]$

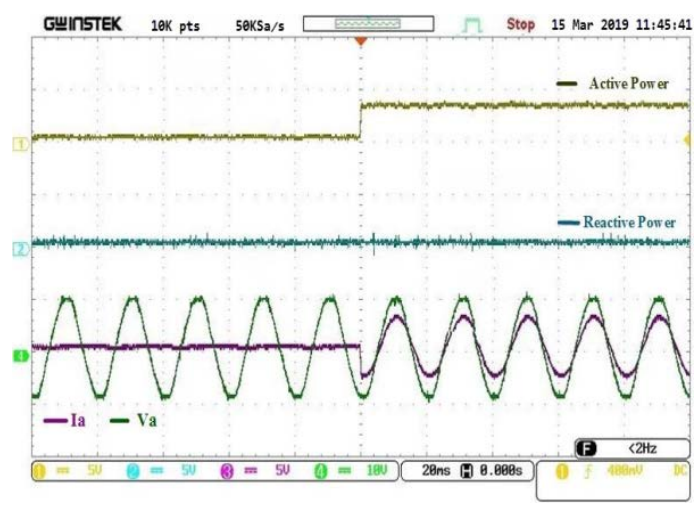

Fig. 34: Laboratory results for the changing step for the active power whereas the reactive power $=0$, [Scale: V: $150 \mathrm{~V} / \mathrm{div}, \mathrm{I}: 5 \mathrm{~A} / \mathrm{div}, \mathrm{P}: 1000 \mathrm{~W} / \mathrm{div}$, t: 20 msec/div]

Transitional period: The process of the transient response includes the readings and information and data of the active and reactive power, the graph of Fig. 34 shows the transient response in the case of changing step for the active power in the meanwhile there is no injection for the reactive power, the current which has been injected is in phase with the voltage phase graph of Fig. 35 explains the changing step in reactive power in the meanwhile there is no injection for the active power, the current which has been injected is $90^{\circ}$ lag by the voltage of the grid. Figure 36 illustrate the performance of the system during the changing of step for the reactive power, after the changing step both of active and reactive power are equal, the procedure is switched from the power factor unity to the power factor $\left(45^{\circ}\right)$ lag and that happens after the changing step for the reactive power source. Figure 37 explains the step change for the reactive and active power which transferred from the power factor unity to the procedure of power factor by 0.7 lag.

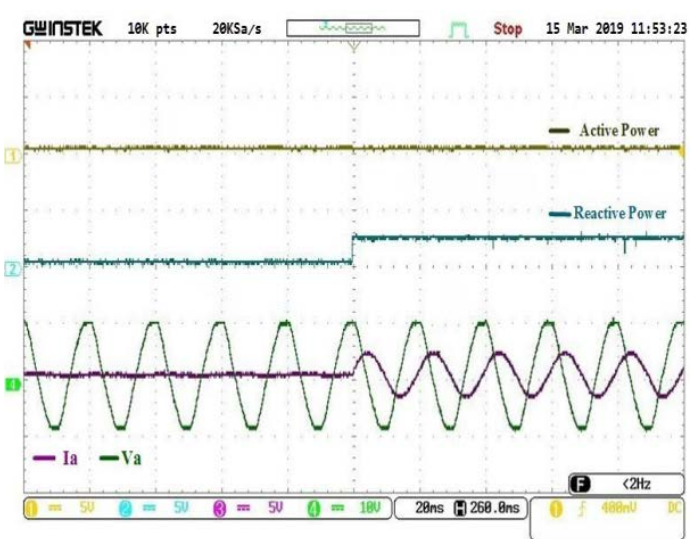

Fig. 35: Laboratory results for changing step for the reactive power whereas the value of the active power $=0$ [Scale: V: $150 \mathrm{~V} / \mathrm{div}, \mathrm{I}: 5 \mathrm{~A} / \mathrm{div}$, P: $1000 \mathrm{~W} / \mathrm{div}, \mathrm{t}: 20 \mathrm{msec} / \mathrm{div}$ ]

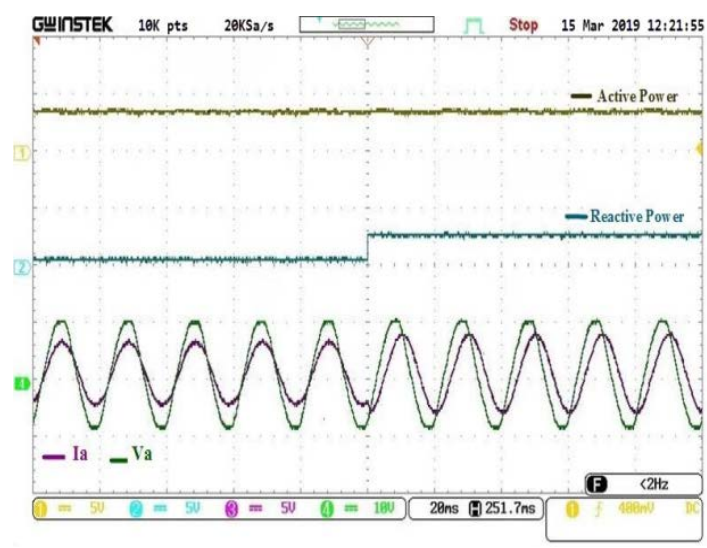

Fig. 36: Laboratory results of the changing step for the reactive power where the active power has fixed value [Scale: V: $150 \mathrm{~V} / \mathrm{div}, \mathrm{I}: 5 \mathrm{~A} / \mathrm{div}, \mathrm{P}: 1000$ W/div, t: $20 \mathrm{msec} / \mathrm{div}]$

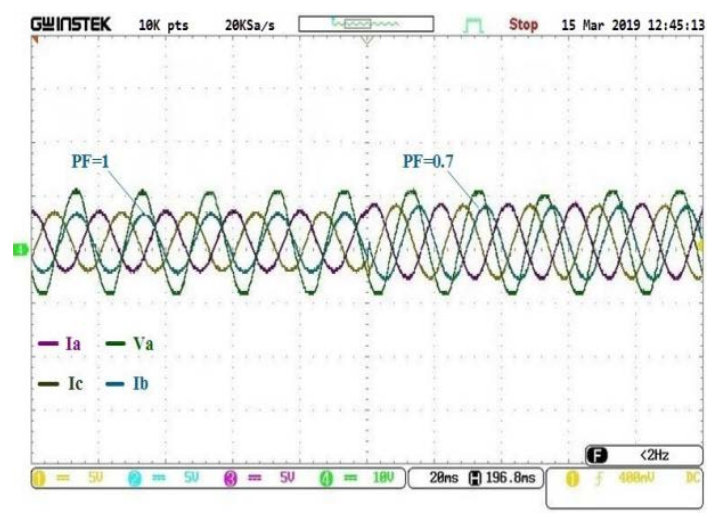

Fig. 37: Laboratory results of changing step for the active and reactive power from power factor unit to (0.7 lag) power factor process [Scale: V: 150 V/div, I: 5 A/div, P: 1000 W/div, t: 20 msec/div] 


\section{CONCLUSION}

This study has presented a three-phase designed inverter connected to PV system which has features of a high performance and clean produced energy. A model of three-phase designed inverter connected to the grid has been established and supplied with suitable programming circuits. The controlling task consists of two basics control circuits as follow; the current control circuit and the dc-link voltage circuit, the PI controller function is to dominate the active and reactive power. The proposed technique for the executed system has been exposed to series of procedures like measurements, testing, analysis, simulation using (MATLAB/Simulink), designing and developing of circuits, recording and detecting results and notes, sketching and comparing resulted values for the experimental results. Eventually, the injection of power into the grid, power factor unit and pure sinusoidal curves have been represented using waveforms and MATLAB/Simulink. Moreover, all the previous processes proved that the selected technique for executing the system has been designed and implemented in a very good approach.

\section{REFERENCES}

Adzic, E., Z. Ivanovic, M. Adzic and V. Katic, 2009. Maximum power search in wind turbine based on fuzzy logic control. Acta Polytech. Hungarica, 6: 131-149.

Blaabjerg, F., M. Liserre and K. Ma, 2011. Power electronics converters for wind turbine systems. IEEE. Trans. Ind. Appl., 48: 708-719.

Blaabjerg, F., Z. Chen and S.B. Kjaer, 2004. Power electronics as efficient interface in dispersed power generation systems. IEEE Trans. Power Electron., 19: 1184-1194.

Carrasco, J.M., L.G. Franquelo, J.T. Bialasiewicz, E. Galvan and R.P. Guisado et al., 2006. Power-electronic systems for the grid integration of renewable energy sources: A survey. IEEE Trans. Ind. Electron., 53: 1002-1016.

Chung, S.K., 2000. A phase tracking system for three phase utility interface inverters. IEEE Trans. Power Electron., 15: 431-438.

Guo, X.Q. and W.Y. Wu, 2013. Simple synchronisation technique for three-phase grid-connected distributed generation systems. IET. Renewable Power Gener., 7: 55-62.

Kanchev, H., D. Lu, F. Colas, V. Lazarov and B. Francois, 2011. Energy management and operational planning of a microgrid with a PV-based active generator for smart grid applications. IEEE. Trans. Ind. Electron., 58: 4583-4592.

Lal, V.N. and S.N. Singh, 2015. Control and performance analysis of a single-stage utility-scale grid-connected PV system. IEEE. Syst. J., 11: 1601-1611.
Magdy, G., G. Shabib, A.A. Elbaset and Y. Mitani, 2019. Renewable power systems dynamic security using a new coordination of frequency control strategy based on virtual synchronous generator and digital frequency protection. Intl. J. Electr. Power Energy Syst., 109: 351-368.

Meneses, D., F. Blaabjerg, O. Garcia and J.A. Cobos, 2012. Review and comparison of step-up transformerless topologies for photovoltaic ACmodule application. IEEE. Trans. Power Electron., 28: 2649-2663.

Moukhtar, I., A.A. Elbaset, A.Z. El Dein, Y. Qudaih and Y. Mitani, 2018. Concentrated solar power plants impact on PV penetration level and grid flexibility under Egyptian climate. AIP. Conf. Proc., Vol. 1968, 10.1063/1.5039224

Ozbay, H., S. Oncu and M. Kesler, 2017. SMC-DPC based active and reactive power control of grid-tied three phase inverter for PV systems. Intl. J. Hydrogen Energy, 42: 17713-17722.

Pastor, M. and J. Dudrik, 2013. Predictive current control of grid-tied cascade H-bridge inverter. Automatika, 54: 308-315.

Prodanovic, M. and T.C. Green, 2003. Control and filter design of three-phase inverters for high power quality grid connection. IEEE. Trans. Power Electron., 18: 373-380.

Ramonas, C. and V. Adomavicius, 2013. Research of the converter control possibilities in the grid-tied renewable energy power plant. Elektronika ir Elektrotechnika, 19: 37-40.

Salem, M. and Y. Atia, 2014. Design and implementation of predictive current controller for photovoltaic gridtie inverter. WSEAS. Trans. Syst. Contr., 9: 597-605.

Sarkar, D.U. and H.S. Dalvi, 2017. Modeling and designing of solar photovoltaic system with 3 phase grid connected inverter. Proceedings of the 2017 2nd International Conference for Convergence in Technology (I2CT’17), April 7-9, 2017, IEEE, Mumbai, India, pp: 1018-1023.

Singh, M., V. Khadkikar and A. Chandra, 2011. Grid synchronisation with harmonics and reactive power compensation capability of a permanent magnet synchronous generator-based variable speed wind energy conversion system. IET. Power Electron., 4: $122-130$.

Susheela, N. and P.S. Kumar, 2017. Performance evaluation of carrier based PWM techniques for hybrid multilevel inverters with reduced number of components. Energy Procedia, 117: 635-642.

Suyata, T.I. and S. Po-Ngam, 2014. Simplified active power and reactive power control with MPPT for three-phase grid-connected photovoltaic inverters. Proceedings of the 2014 11th International Conference on Electrical Engineering/ Electronics, Computer, Telecommunications and Information Technology (ECTI-CON'14), May 14-17, 2014, IEEE, Nakhon Ratchasima, Thailand, pp: 1-4. 
Suyata, T.I., S. Po-Ngam and C. Tarasantisuk, 2015. The active power and reactive power control for three-phase grid-connected photovoltaic inverters. Proceedings of the 2015 12th International Conference on Electrical Engineering/ Electronics, Computer, Telecommunications and Information Technology (ECTI-CON'15), June 24-27, 2015, IEEE, Hua Hin, Thailand, pp: 1-6.
Yan, L., X. Li, H. Hu and B. Zhang, 2011. Research on SVPWM inverter technology in wind power generation system. Proceedings of the 2011 International Conference on Electrical and Control Engineering, September 16-18, 2011, IEEE, Yichang, China, pp: 1220-1223.

Yao, Z., L. Xiao and J.M. Guerrero, 2015. Improved control strategy for the three-phase grid-connected inverter. IET. Renewable Power Gener., 9: 587-592. 